\title{
Myxoid malignant fibrous histiocytoma with multiple primary sites
}

\author{
JEFFREY H. MULER ${ }^{1}$, AUGUSTO F. PAULINO ${ }^{2}$, DIANE ROULSTON ${ }^{2}$ \& LAURENCE \\ H. BAKER ${ }^{3}$
}

Departments of ${ }^{1}$ Hematology/Oncology and ${ }^{2}$ Pathology, University of Michigan, and ${ }^{3}$ University of Michigan Cancer Center, Ann Arbor, MI, USA

\begin{abstract}
Malignant fibrous histiocytoma $(\mathrm{MFH})$ is one of the most common types of soft tissue sarcomas in adults. The most common location of $\mathrm{MFH}$ are the extremities and the trunk, with the most common site for distant metastases being the lung. We describe a case with multiple synchronous sites of myxoid MFH but no lung metastases and presence of abnormalities of $19 \mathrm{p} 13$.
\end{abstract}

\section{Introduction}

Malignant fibrous histiocytoma (MFH) is one of the most common types of soft tissue sarcomas in adults, ${ }^{1,2}$ with the majority of tumors arising in the trunk or the extremities. About $30-40 \%$ of patients with $\mathrm{MFH}$ develop distant metastases, with the most common site being the lung. ${ }^{3-7}$ Metastatic disease in the absence of lung metastases is highly unusual. This report describes a case in which a patient had multiple synchronous myxoid MFH tumors without evidence of lung metastases. We believe that the patient had multiple primary sites of myxoid $\mathrm{MFH}$, thus raising the possibility of a genetic abnormality that could predispose such a patient to develop multiple sites of the same tumor. The description of the tumor karyotype in the case of our patient is provided.

\section{Case report}

The patient was a 67-year-old man who originally noticed a lump in his right calf area 3 years previously. Magnetic resonance imaging at that time confirmed a tumor in the right calf, and a core needle biopsy revealed high-grade myxoid malignant fibrous histiocytoma (MFH) (Fig. 1). The patient was treated with neoadjuvant chemotherapy (mesna, doxorubicin, ifosfamide and dacarbazine) and underwent tumor resection followed by adjuvant radiation. He remained well until 2 years later when he noticed two $10-\mathrm{cm}$ lumps in the upper right thigh and pain in the epigastric area. A computerized tomography scan of the abdomen performed at that time revealed a gastric mass, and the patient underwent excision of the two thigh tumors followed by partial gastrectomy. The pathology from all three sites was reviewed and revealed high-grade myxoid $\mathrm{MFH}$ in each of them (Figs. 2 and 3). The surgical margins of the two thigh lesions resected were negative. The CD117 (c-kit) stains performed on the partial gastrectomy specimen were negative. The patient remained well for 3 months, when he presented to our institution with a rapidly enlarging mass on the right forearm. Staging CT scans preoperatively revealed no evidence of pulmonary or abdominal metastasis and patient underwent wide excision of the right forearm lesion, which again turned out to be high-grade myxoid $\mathrm{MFH}$.

Cytogenetic analysis was performed on the fresh samples from the right forearm excision. An abnormal clone with complex cytogenetic abnormalities was observed, that had the following hypodiploid karyotype: $39, \operatorname{der}(\mathrm{X} ; 6) \operatorname{idic}(6)(\mathrm{q} 12) \mathrm{t}(6 ; 8)(\mathrm{p} 23 ; \mathrm{q} 13)$ $\mathrm{t}(\mathrm{X} ; 6)(\mathrm{p} 22.1 ; \mathrm{p} 23),-\mathrm{Y},-1, \operatorname{der}(1) \mathrm{t}(1 ; 15)(\mathrm{p} 31 ; \mathrm{q} 13), \mathrm{der}$ $(3 ; 9) \mathrm{t}(3 ; 9)(\mathrm{p} 26 ; \mathrm{q} 34) \operatorname{add}(9)(\mathrm{p} 24), \mathrm{i}(4)(\mathrm{p} 10), \operatorname{der}(6)$ $\mathrm{t}(2 ; 6)$ (q31;q27)ins (6;?) (q27;?), add (7) (q32), der(7) $\mathrm{t}(7 ;$ ? 1 1) (q36;q2 1)ins(7;?) (q36;?),-8, -8,-10, del(11) (p11.1p 15.5),-13,-13,+14, der(14) t $(3 ; 14)$ (p21; q32),-15, der(15)t(15;?22)(p11.2; q11.2),-17,-17,18 ,ins (18;?) (p11.2;?), add (19) (p13.1), del(19) (p13.2p13.3),+22, del(22)(q13.1q13.3), der(22)del 


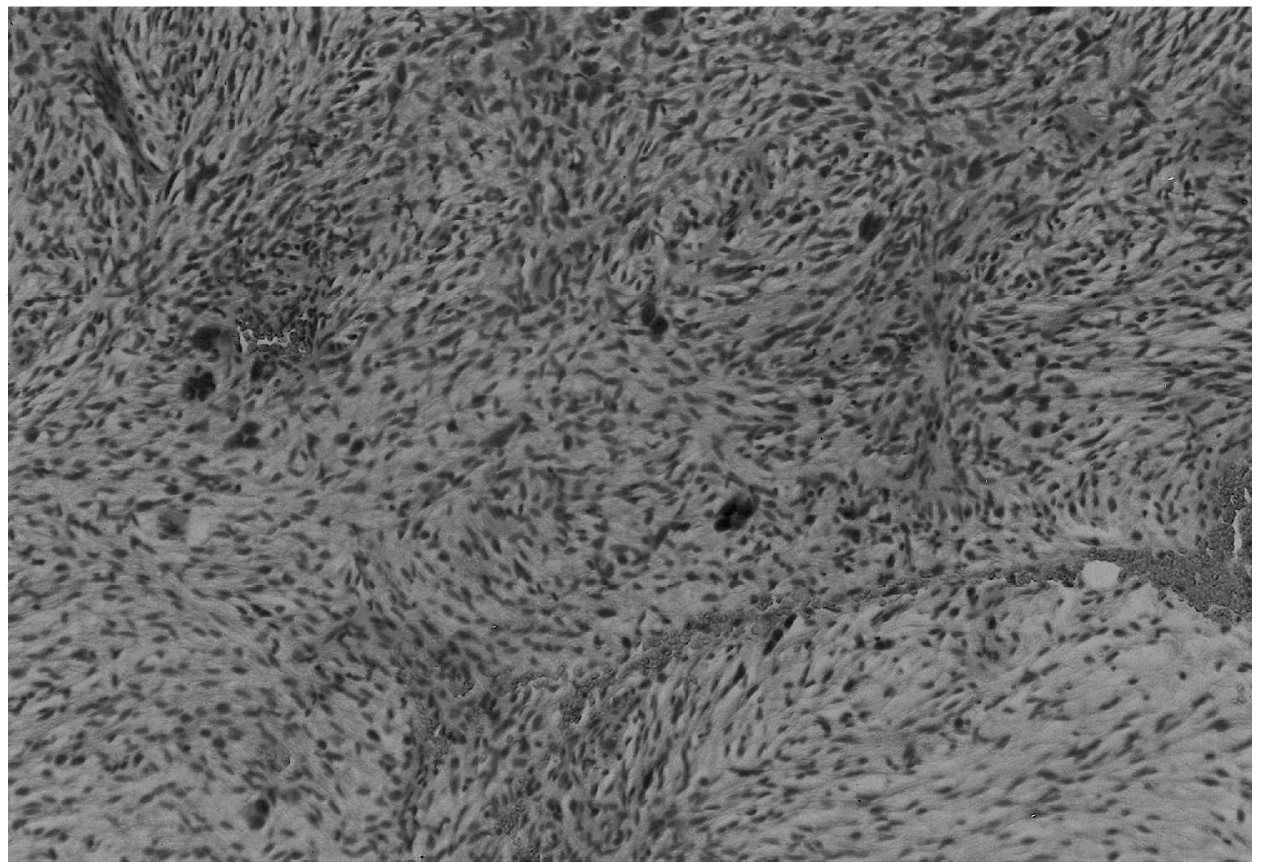

Fig. 1. HEE stain right calf biopsy, $\times 200$.

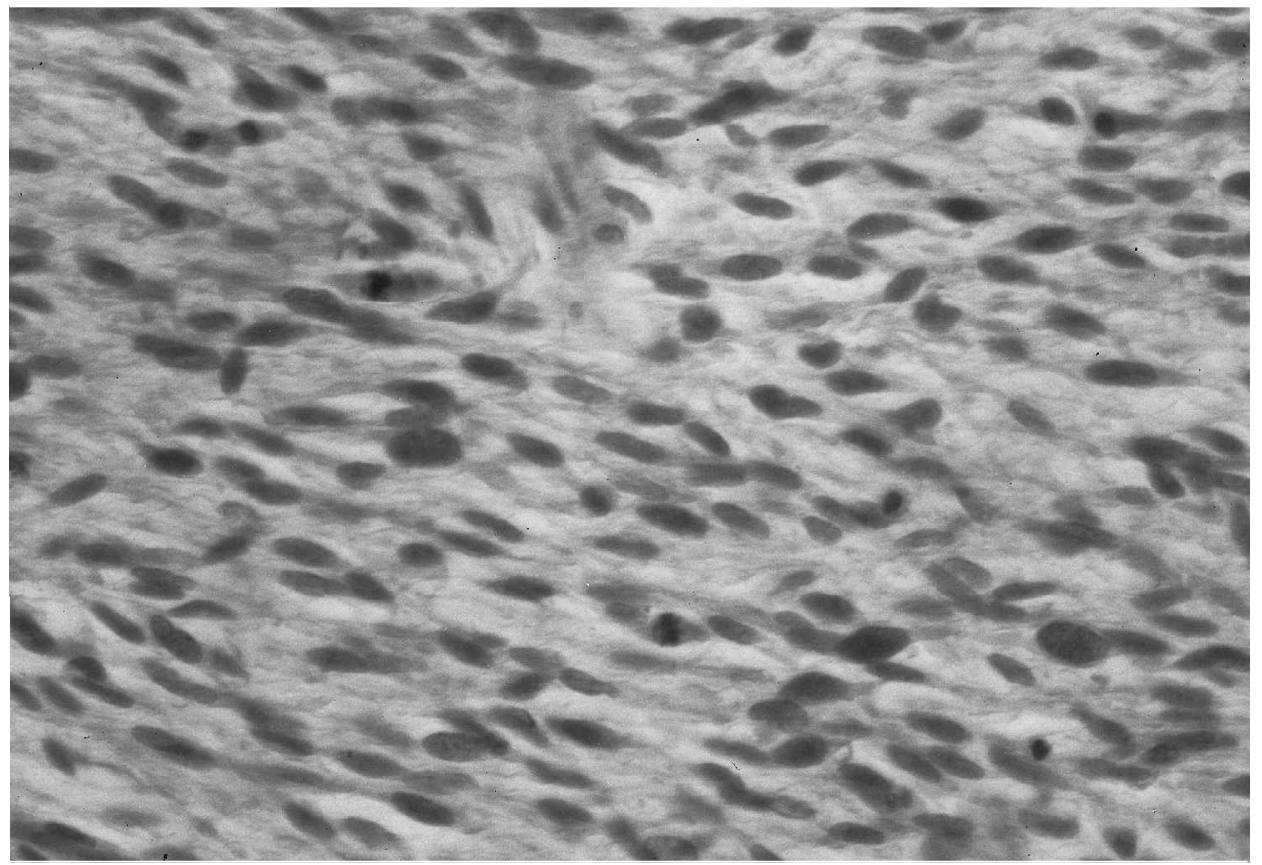

Fig. 2. HEE stain right thigh resection, $\times 400$.

(22)(p11.1p13)del(22)(q12q13), + mar 1, + mar 2, + mar 3 .

\section{Discussion}

Malignant fibrous histiocytoma (MFH) is considered to be one of the most common types of soft tissue sarcomas in adults, accounting for $36-40 \%$ of all soft tissue sarcomas analyzed in two large series. ${ }^{1,2}$ The majority of $\mathrm{MFH}$ arise in the proximal extremities or the trunk. ${ }^{2-4}$ The incidence of $\mathrm{MFH}$ increases with age, with the majority of patients being over 50 years of age. ${ }^{4}$ The local recurrence rate for $\mathrm{MFH}$ is $28-51 \%$ depending on whether adjuvant radiation was used..$^{2-6}$ The rate of distant metastasis varies from 30 to $46 \% .^{2,3,5,7}$ The most common site of distant metastasis was by far the lung (63-91\%), followed by lymph nodes $(10 \%)$ and bone $(3-8 \%)$, taken as a proportion of all metastatic sites. ${ }^{3,4,7}$ Table 1 illustrates the overall survival (OS) and disease-free survival (DFS) for $\mathrm{MFH}$ from various reported series: 


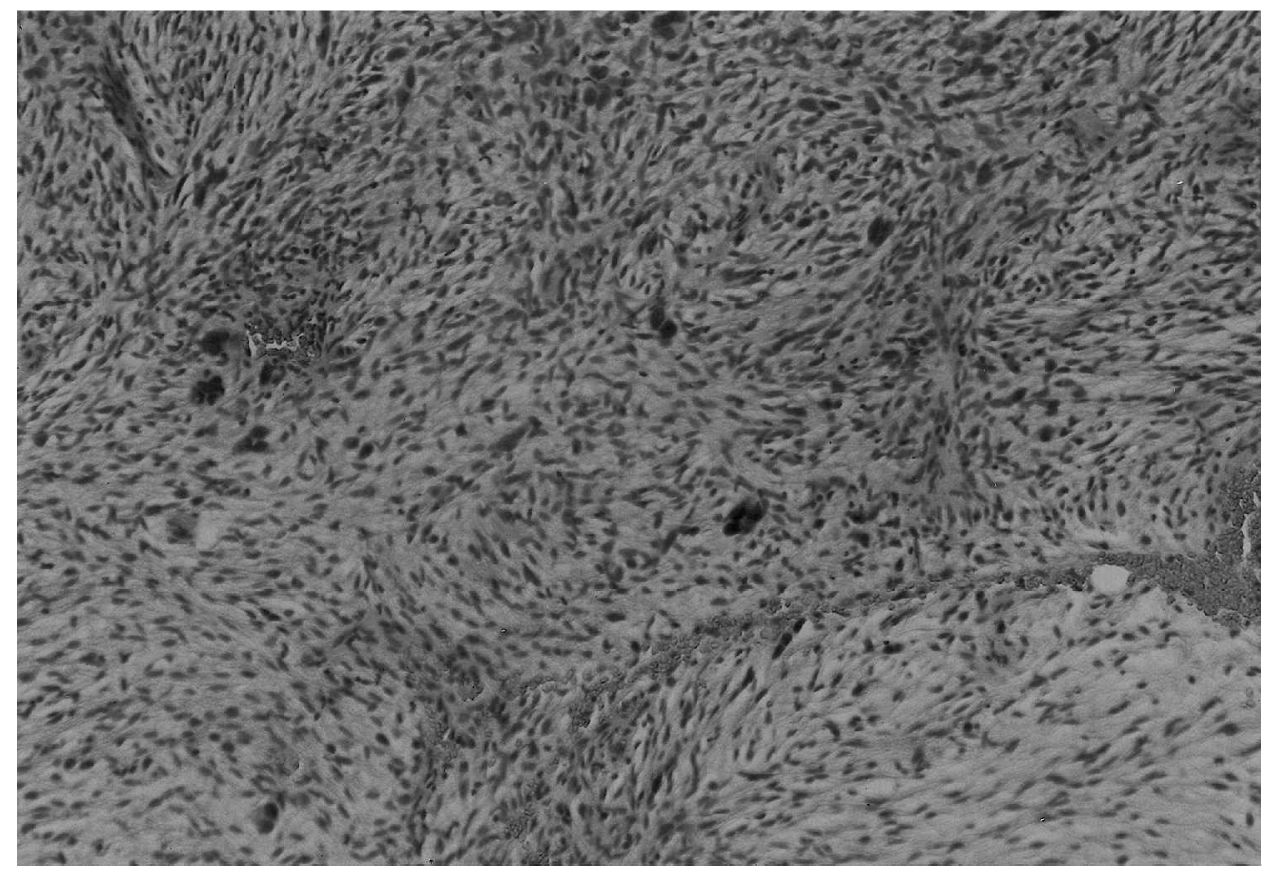

Fig. 3. HEE stain mass from partial gastrectomy, $\times 400$.

Table 1. Overall and disease-free survival in $M F H$

\begin{tabular}{lccc}
\hline Ref. & $\begin{array}{c}\text { OS at } 5 \text { years } \\
(\%)\end{array}$ & $\begin{array}{c}\text { DFS at 5 years } \\
(\%)\end{array}$ & $\begin{array}{c}\text { Median follow-up } \\
\text { (months) }\end{array}$ \\
\hline 4 & 67.2 & 50.6 & 73 \\
5 & 58 & 36 & 42 \\
7 & 36 & NA & 72 \\
8 & 70 & NA & 36 \\
\hline
\end{tabular}

Abbreviations: OS, overall survival; DFS, disease-free survival.

Table 2. Significant prognostic factors in $M F H$

\begin{tabular}{lcc}
\hline Factor & Outcome influenced & Ref. \\
\hline Tumor size & MFS, OS & $2,3,4,5,7,8$ \\
Subtype: myxoid versus non-myxoid & MFS, DSS, OS & $2,3,8$ \\
Tumor necrosis & MFS, OS & 2,8 \\
UICC Stage III+IVA & DSS & 3 \\
Deep tumor location & DSS & 3,6 \\
$\quad$ Age $>$ 50 & DSS & 3 \\
Grade & MFS, OS & $3,4,5$ \\
Negative margins after primary resection & LRFS, DFS, OS & $3,5,7$ \\
\hline
\end{tabular}

Abbreviations: MFS, metastasis free survival; DSS, disease-specific survival; OS, overall survival; DFS, disease-free survival; LRFS, local recurrence-free survival.

A number of prognostic factors have been examined in terms of their predictive significance for overall survival and recurrence in $M F H$ by various investigators, in an attempt to better define different prognostic variables in this diverse group of soft tissue sarcomas (Table 2).

There are four major variants of $\mathrm{MFH}$ recognized today: storiform-pleomorphic (the most common), myxoid, giant cell and inflammatory. ${ }^{9}$ The myxoid type of MFH (also known as myxofibrosarcoma) accounts for about a third of all MFH cases. ${ }^{2,9}$ This subtype of $\mathrm{MFH}$ was first described by several authors in the late 1970s, and was based on its distinct gelatinous appearance grossly, with a variable amount of myxoid stroma adjacent to the cellular areas microscopically. ${ }^{10-12}$

The median age at diagnosis of myxoid MFH is 65 years ${ }^{13}$ with peak incidence at $60-69$ years. ${ }^{11}$ The most common primary site was the extremities $(77 \%)$, the trunk (15\%) and the retroperitoneum $(8 \%) .{ }^{13} \mathrm{In}$ $70 \%$ of cases, the primary tumor was subcutaneous at presentation. ${ }^{13}$ It has been argued that the myxoid type represents a distinct subgroup of MFH based on its better prognosis compared to the other $\mathrm{MFH}$ 
variants. ${ }^{12}$ The reported rates of recurrencevary from 52 to $66 \% .^{11,13}$ Metastasis occurred in $23-35 \%$ of cases, with the most common site of metastasis being the lungs, followed by the lymph nodes, skeleton and liver. ${ }^{11,13}$ Mentzel et al. have described a low-grade variant of myxofibrosarcoma, with an even lower incidence of distant metastasis. ${ }^{14}$ Within this group, the authors described five cases in which the low-grade myxofibrosarcoma tended to become progressively higher grade with each recurrence. ${ }^{14}$

Factors that are believed to favorably influence recurrence rates and metastasis in myxoid $\mathrm{MFH}$ include: small size, superficial location, increased proportion of the myxoid component and low grade. ${ }^{11,14}$ In the original Scandinavian series on myxoid $\mathrm{MFH}$, the 5- and 10-year survival rates were 65 and $52 \%$, respectively. ${ }^{13}$ Histological grade, type of surgical therapy, tumor size, age, and interval to first recurrence were important predictors for survival and recurrence. ${ }^{13}$

The case reported here has an unusual feature, in that the patient may have had what we believe to be multiple new primary sites of $\mathrm{MFH}$ in locations such as soft tissues of the extremities, without evidence of metastases to the lung parenchyma.

There are two possible explanations for such an unusual clinical course. It is conceivable that the reason our patient did not have lung metastases is because the multiple recurrences represent separate myxoid MFH primary sites. The superficial location of the patient's lesions would place him at a lower risk for distant metastases, as superficial location of the tumor had a higher local recurrence rate but a decreased incidence of distant metastases compared to the deep lesions. ${ }^{3,6,11}$ Myxoid $\mathrm{MFH}$ primary tumors have been known to present as superficial lesions in up to $70 \%$ of cases. ${ }^{13,14}$ An alternative explanation is that the patient developed multiple subcutaneous metastases over the clinical course of the disease. Coincidental second primary tumors previously described with myxoid $\mathrm{MFH}$ include: palmar fibromatosis, lipomas, basal cell carcinomas of the skin, carcinomas of the large bowel and stomach, and carcinomas of the ovary and uterus. ${ }^{13}$ However, only one case in the early original series on myxoid $\mathrm{MFH}$ described a patient with multiple synchronous tumors on the arm, buttock and shoulder. ${ }^{11}$

The absence of ring chromosomes and the presence of $19 p+$ marker in our case would be consistent with an increased relapse rate, both locally and distally, and would support the distant metastases point of view. ${ }^{20,21}$

None of the above arguments disprove that the multiple lesions could have represented distant metastases. After all, our myxoid MFH lesions were high grade with a small myxoid component, a finding associated with a $24-31 \%$ rate of distant metastasis. ${ }^{11}$ However, such a pattern without pulmonary involvement is highly unusual. An early series on myxoid MFH described two patients with a similar clinical course of multiple subqutaneous recurrences and involvement of the GI tract. ${ }^{10}$ Both patients developed pulmonary metastases, while the patient in our case did not.

Despite its being one of the most common types of soft tissue sarcomas in many published clinical series, the validity of classifying certain types of $\mathrm{MFH}$ as separate histopathological entities has been questioned. ${ }^{15,16}$ In a recent study by Fletcher et al., ${ }^{17}$ of 61 cases initially labeled as storiformpleomorphic $\mathrm{MFH}$, all but one case was reclassified using predefined histopathological criteria proposed by the authors. Myxoid MFH (myxofibrosarcoma) on the other hand, remained the most common subtype in that series. Thus, it appears that myxoid $\mathrm{MFH}$ is one subtype of $\mathrm{MFH}$ that represents a distinct reproducible entity. ${ }^{18}$

Advances in various techniques of chromosomal analysis have prompted many investigators to try and define $\mathrm{MFH}$ on a more basic molecular level. The earlier studies revealed a clonal chromosomal abnormality in 17 out of 25 cases of $\mathrm{MFH}$, with further observation that the presence of an abnormal $19 \mathrm{p}^{+}$marker chromosome was associated with increased frequency of local recurrence. $^{19-21}$ Breakpoints in $1 \mathrm{q} 11,1 \mathrm{p} 36,3 \mathrm{p} 12$, $11 \mathrm{p} 11$ and $19 \mathrm{p} 13$ were frequently observed. ${ }^{19}$ Another group reported two cases with sole abnormalities of $\mathrm{t}(5 ; 7)(\mathrm{q} 31 ; \mathrm{q} 22)$ and $\operatorname{der}(13 ; 14)(\mathrm{q} 10 ; \mathrm{q} 10)$, raising the possibility that they represent primary cytogenetic abnormalities. ${ }^{22}$ Using the technique of comparative genomic hybridization, investigators in one study were able to demonstrate that gain of $7 q 32$ was associated with decreased metastasis-free survival and overall survival, whereas gain of $1 \mathrm{p} 31$ was associated with a trend towards decreased overall survival. ${ }^{23}$

The cytogenetic findings in our case revealed abnormalities of 19 p13 for both of the homologues that were present, an abnormality reported to have adverse prognostic significance with increased rates of recurrence and metastasis. ${ }^{19-21}$ A trend towards fewer relapses in tumors with ring chromosomes was noted in one of the series. ${ }^{21}$ Of note, no ring chromosomes were found in our case. Previously reported abnormalities also found in our case include: presence of hypodiploid clone, abnormality of $9 p$ and $11 \mathrm{p} 11$, and presence of dicentric chromosomes $\operatorname{der}(\mathrm{X} ; 6), \operatorname{der}(3 ; 9)$ are dicentric.

Several candidate genes implicated in the pathogenesis of $\mathrm{MFH}$ have been recently identified. Frequent amplification in the region of 8 p23.1 in eight out of $14 \mathrm{MFHs}$ has led one group of investigators to identify a novel gene MASL1 located in this narrow region. ${ }^{24}$ The product of this gene is believed to be an ATP/GTP-binding protein involved in the regulation of the cell cycle. Frequent loss of region 13q12-q14 and $13 \mathrm{q} 21$, reported in $78 \%$ of $\mathrm{MFHs}$ analyzed in one series, led the authors to believe that mutation or inactivation of the $R B 1$ tumor suppressor gene could 
be an initial event in the pathogenesis of $\mathrm{MFH} .{ }^{25,26}$ Mutations of TP53 tumor suppressor gene were also demonstrated in series on MFH. ${ }^{27,28}$ Finally, presence of a shared deletion of $9 \mathrm{p} 21$ between a rare inherited form of $\mathrm{MFH}$ and sporadic $\mathrm{MFH}$ indicated that the tumor suppressor genes present in that location $C D K N 2 A / B$ could contribute to tumorigenesis in $\mathrm{MFH} .{ }^{29}$ This hypothesis is supported by one recent study, which identified frequent loss of $9 \mathrm{p} 21$ leading to the deletion of the $C D K N 2 A$ gene in up to $55 \%$ of $\mathrm{MFH}$ cases analyzed. ${ }^{28}$

Of note, however, no single cytogenetic or molecular rearrangement exists that has been shown to be pathognomonic of MFH. It has been argued that the broad range of complex rearrangements frequently reported with $\mathrm{MFH}$ stems from the possibility that the cases represent groups of heterogeneous sarcomas. ${ }^{22}$

In conclusion, we report a case of myxoid $\mathrm{MFH}$ with possibly multiple primary sites, absence of pulmonary metastases and presence of an abnormality of $19 \mathrm{p} 13$. This, in turn, raises the possibility of a yet undetermined germ line mutation specific for MFH in such a patient, that could account for the development of multiple primary sites of the same tumor. It also demonstrates that within the spectrum of $\mathrm{MFH}$, subgroups of patients may have a distinct clinical course based on the different molecular pathogenesis of certain types of MFH. Further studies aimed at determining the exact cellular aberrations associated with this neoplasm and their clinical significance are warranted.

\section{References}

1. Coindre JM, Terrier P, Binh Bui N, et al. Prognostic factors in adult patients with locally controlled soft tissue sarcoma: a study of 546 patients from the French Federation of Cancer Centers Sarcoma Group. 7 Clin Oncol 1996; 14: 869-77.

2. Gustafson P. Soft tissue sarcoma: epidemiology and prognosis in 508 patients. Acta Orthopaedica Scand 1994; 65 (Suppl 259): 1-29.

3. Le Doussal V, Coindre JM, Leroux A, et al. Prognostic factors for patients with localized primary malignant fibrous histiocytoma: a multicenter study of 216 patients with multivariate analysis. Cancer 1996; 77: 1823-30.

4. Pezzi CM, Rawlings MS, Esgro JJ, et al. Prognostic factors in 227 patients with malignant fibrous histiocytoma. Cancer 1992; 69: 2098-103.

5. Gibbs JF, Huang PP, Lee JR, et al. Malignant fibrous histiocytoma: an institutional review. Cancer Invest $2001 ; 19(1): 23-7$.

6. Kearney MM, Soule EH, Ivins JC. Malignant fibrous histiocytoma: a retrospective study of 167 cases. Cancer 1980; 45: 167-78.

7. Bertoni F, Capanna R, Biagini R, et al. Malignant fibrous histiocytoma of soft tissue. Cancer 1985; 56: 356-67.

8. Rooser B, Willen H, Gustafson P, et al. Malignant fibrous histiocytoma of soft tissue. Cancer 1991; 67: 499-505.

9. Enzinger FM, Weiss SW. Soft Tissue Tumors, 3rd ed. St Louis, MO: Mosby, 1995; 351-80.
10. Angervall L, Kindblom LG, Merck C. Myxofibrosarcoma. Acta Pathol Microbiol Scand Sect A 1977; 85: 127-40.

11. Weiss SW, Enzinger FM. Myxoid variant of malignant fibrous histiocytoma. Cancer 1977; 39: 1672-85.

12. Weiss SW. Malignant fibrous histiocytoma. A reaffirmation. Am f Surg Pathol 1982; 6: 773-84.

13. Merck C, Kindblom LG, Oden A. Myxofibrosarcoma: a malignant soft tissue tumor of fibroblastic-histiocytic origin. Acta Pathol Microbiol Scand Sect A 1983; 91 (Suppl 282): 1-40.

14. Mentzel T, Calonje E, Wadden C, et al. Myxofibrosarcoma: clinicopathologic analysis of 75 cases with emphasis on the low-grade variant. Am $\mathcal{F}$ Surg Pathol 1996; 20: 391-405.

15. Fletcher CDM. Malignant fibrous histiocytoma? Histopathology 1987; 11: 433-7.

16. Fletcher CDM. Pleomorphic malignant fibrous histiocytoma: Fact or fiction? A critical reappraisal based on 159 tumors diagnosed as pleomorphic sarcoma. $A m \mathcal{F}$ Surg Pathol 1992; 16: 213-28.

17. Fletcher CDM, Gustafson P, Rydholm A, et al. Clinicopathologic re-evaluation of 100 malignant fibrous histiocytomas: prognostic relevance of subclassification. $\mathcal{F}$ Clin Oncol 2001; 19: 3045-50.

18. Hollowood K, Fletcher CDM. Malignant fibrous histiocytoma: morphologic pattern or pathologic entity? Semin Diagn Pathol 1995; 12: 210-20.

19. Mandahl N, Heim S, Willen H, et al. Characteristic karyotypic anomalies identify subtypes of malignant fibrous histiocytoma. Genes Chromosomes Cancer 1989; 1: 9-14.

20. Rydholm A, Mandahl N, Heim S, et al. Malignant fibrous histiocytoma with $19 \mathrm{p}+$ marker chromosome have increased relapse rate. Genes Chromosomes Cancer 1990; 2: 296-9.

21. Choong PFM, Mandahl N, Mertens F, et al. $19 \mathrm{p}+$ Marker chromosome correlates with relapse in malignant fibrous histiocytoma. Genes Chromosomes Cancer 1996; 16: 88-93.

22. Walter TA, Weh HJ, Schlag PM, et al. Cytogenetic studies in malignant fibrous histiocytoma. Cancer Genet Cytogenet 1997; 94: 131-4.

23. Larramendy ML, Tarkkanen M, Blomqvist C, et al. Comparative genomic hybridization of malignant fibrous histiocytoma reveals a novel prognostic marker. Am F Pathol 1997; 151: 1153-61.

24. Sakabe T, Shinomiya T, Mori T, et al. Identification of a novel gene, MASL1, within an amplicon at 8p23.1 detected in malignant fibrous histiocytomas by comparative genomic hybridization. Cancer Res 1999; 59: 511-5.

25. Chibon F, Mairal A, Freneauz P, et al. The RB1 gene is the target of chromosome 13 deletions in malignant fibrous histiocytoma. Cancer Res 2000; 60: 6339-45.

26. Mairal A, Terrier P, Chibon F, et al. Loss of chromosome 13 is the most frequent genomic imbalance in malignant fibrous histiocytoma. Cancer Genet Cytogenet 1999; 111: 134-8.

27. Taubert H, Wurl P, Meye A, et al. Molecular and immunohistochemical p53 status in liposarcoma and malignant fibrous histiocytoma. Cancer 1995; 76: 1187-96.

28. Simons A, Schepens M, Jeuken J, et al. Frequent loss of $9 \mathrm{p} 21$ (p16INK4A) and other genomic imbalances in human malignant fibrous histiocytoma. Cancer Genet Cytogenet 2000; 118: 89-98.

29. Martignetti JA, Gelb BD, Pierce $\mathrm{H}$, et al. Malignant fibrous histiocytoma: inherited and sporadic forms have loss of heterozygosity at chromosome bands 9p21-22 - evidence for a common genetic defect. Genes Chromosomes Cancer 2000; 27: 191-5. 


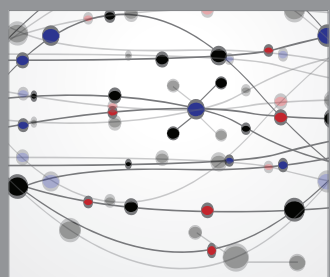

The Scientific World Journal
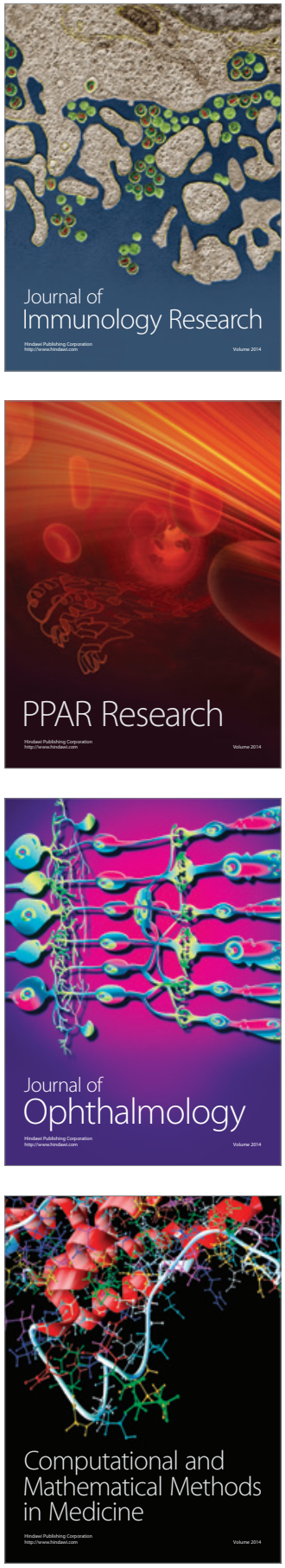

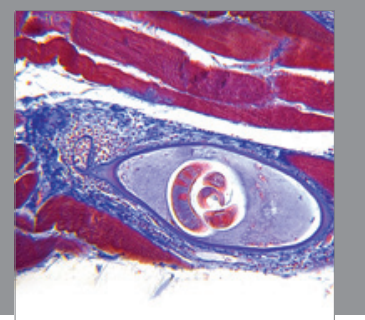

Gastroenterology

Research and Practice
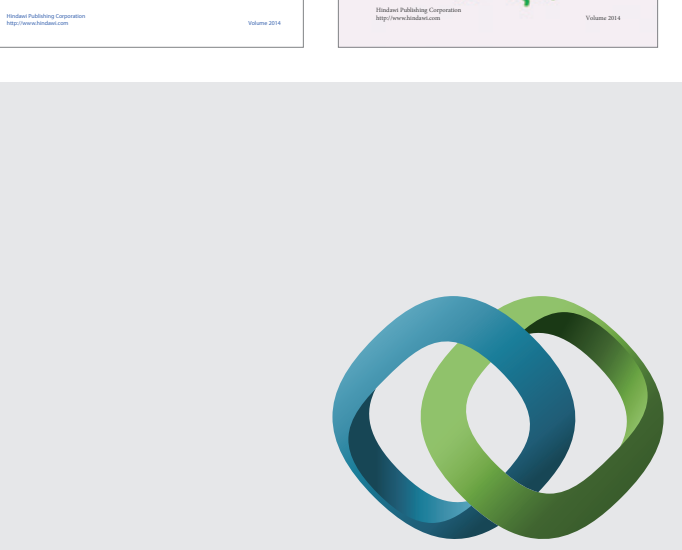

\section{Hindawi}

Submit your manuscripts at

http://www.hindawi.com
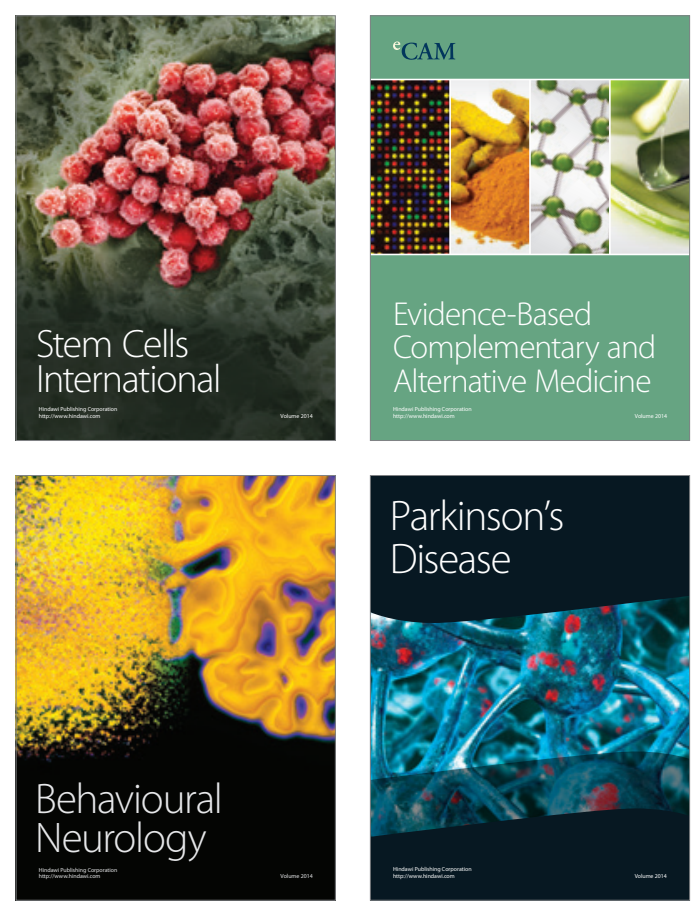

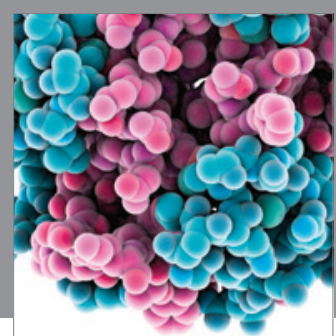

Journal of
Diabetes Research

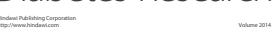

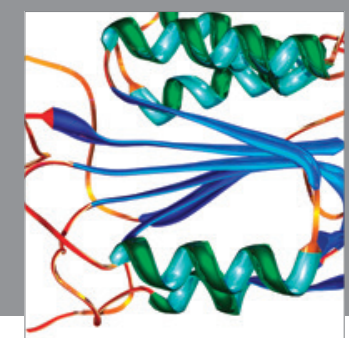

Disease Markers
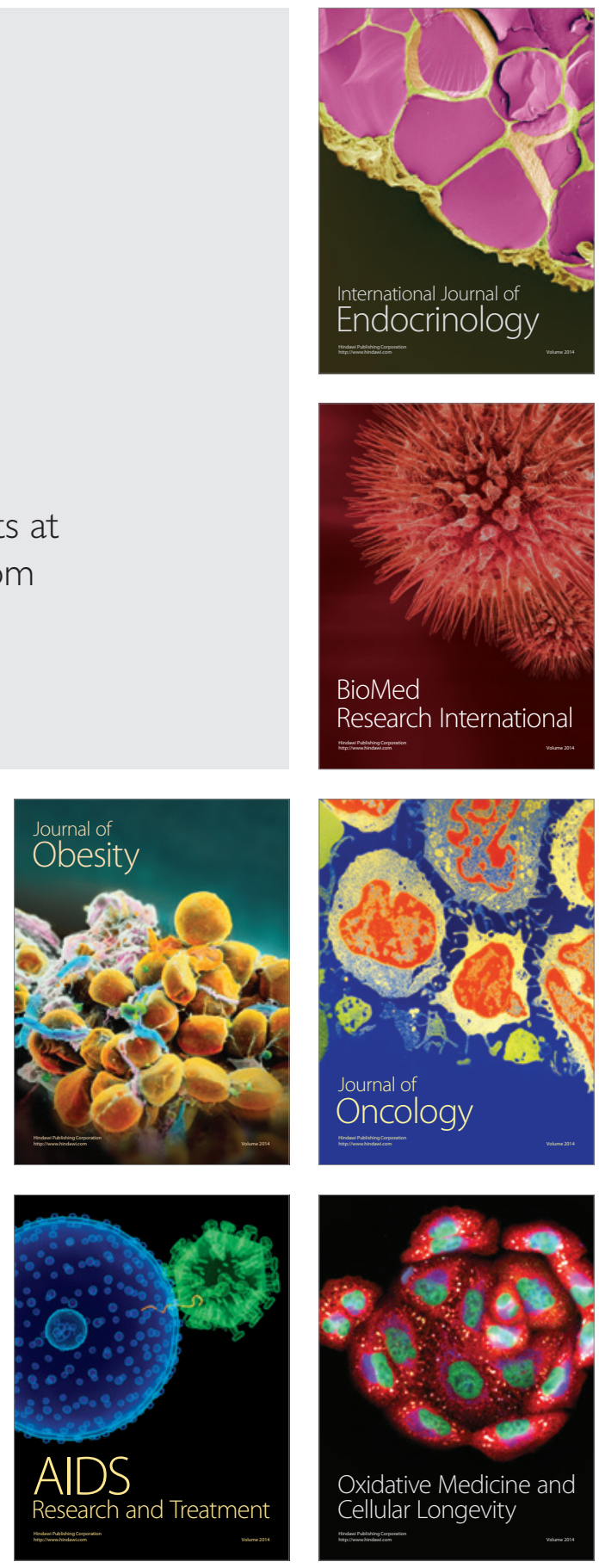